\title{
Model Fuzzy Goal Programming Yang Diselesaikan Dengan Linear Programming Pada Perencanaan Produksi
}

\author{
Altien J. Rindengan ${ }^{1)}$, Prapto Tri Supriyo ${ }^{2)}$, Aziz Kustiyo ${ }^{3)}$ \\ ${ }^{1)}$ Program Studi Mate matika FMIPA UNSRAT, altien@unsrat.ac.id \\ ${ }^{2)}$ Departemen Matematika FMIPA IPB \\ ${ }^{3)}$ Departemen Ilmu Ko mputer FMIPA IPB
}

\begin{abstract}
Optimization of an objective in the model of linear programming (LP) is widely applied in solving the problems that exist. But with the increasing complexity of these problems, optimization with multiple objectives, known as goal programming (GP) being an option. In this GP, some of these goals were weighted before analysis. In this paper will discuss the formulation of fuzzy goal prongramming (FGP), in which these goals need not be discrete weighted, but enough to consider the decision maker wishes to impose limits on the value of each function's purpose. Fuzzy concept of a fuzzy membership function is applied to functions such objectives to be achieved. The problems in this case is production planning at the company with some goals to be achieved namely income, labor costs, and raw material costs. The result is a model with some objectives can be formulated in FGP models that can be solved with the LP for production planning of the company.
\end{abstract}

Keywords : fuzzy goal programming, linear programming, production planning

\begin{abstract}
ABSTRAK
Optima lisasi suatu tujuan dalam model linear programming (LP) banyak diaplikasikan dalam menyelesaikan masalah-masalah yang ada. Tapi dengan makin kompleksnya masalah-masalah tersebut, pengoptimalan dengan beberapa tujuan atau dikenal dengan goal programming (GP) menjadi pilihan. Dalam GP ini, beberapa tujuan ini diberi pembobotan sebelum dianalisa. Dalam tulisan ini akan dibahas tentang formulasi fuzzy goal prongramming (FGP), dimana tujuan-tujuan tersebut tidak perlu diboboti secara diskret, tapi cukup dengan mempertimbangkan keinginan pengambil keputusan untuk menentukan batasan nilai pada setiap fungsi tujuan yang ada. Konsep fuzzy berupa fungsi keanggotaan fuzzy diterapkan pada fungsi-fungsi tujuan yang akan dicapai tersebut. Masalah yang digunakan adalah perencanaan produksi pada suatu perusahaan dengan beberapa tujuan yang ingin dicapai yaitu pendapatan, biaya tenaga kerja, dan biaya bahan baku. Hasil yang diperoleh adalah model beberapa tujuan dapat diformulasi dalam model FGP yang dapat diselesaikan dengan LP untuk perencanaan produksi suatu perusahaan.
\end{abstract}

Kata kunci : fuzzy goal programming, linear programming, perencanaan produksi

\section{Pendahuluan}

Perencanaan produksi ada lah proses untuk memproduksi barang-barang pada suatu periode tertentu sesuai dengan yang diramalkan atau dijadwalkan melalui pengorganisasian sumber daya seperti bahan baku, tenaga kerja, mesin dan alat lainnya. Optimalisasi produksi dapat dinyatakan dalam bentuk pemrograman matematis. Seperti bentuk pengotimuman fungsi tujuan/objektif dengan kendala tertentu dimana metode pengembangan solusi diarahkan ke tujuan tunggal seperti metode simpleks untuk linear programming (LP). Dalam perencanaan produksi juga tidak hanya dilihat dari sisi memproduksi barang semaksimal mungkin, tapi perlu mempertimbangkan batasanbatasan yang mempengaruhinya, misalkan ketersediaan bahan baku yang terbatas atau ada tujuan lain yang juga harus dicapai.

Metode yang mempertimbangkan beberapa tujuan dalam model LP disebut dengan multiobjective linear programming (MOLP) atau goal programming (GP) yang merupakan salah satu metode dalam pengambilan keputusan multi-kriteria. Chodary dan Slomp (2002) memaparkan bahwa GP dapat diterapkan secara efektif dalam perencanaan produksi, karena metode GP potensial untuk menyelesaikan aspek-aspek yang bertentangan antara elemen-elemen dalam perencanaan produksi, yaitu konsumen, produk, dan proses manufaktur.

Selain itu, dilihat dari pembuat keputusan, maka tingkat aspirasi pembuat keputusan harus dipertimbangkan untuk memecahkan masalah dari perspektif strategi kepuasan. Menurut 
Chankong dan Haimes (1993), unsur penilaian manusia adalah di bidang preferensi didefinisikan oleh pembuat keputusan. Menurut Cukas (2008), proses keputusan dengan beberapa kriteria dalam bisnis dan teknik mengarah pada konsep fuzzy mutiobjective linear programming. Model ini juga dikenal dengan fuzzy goal programming (FGP). Dibandingkan dengan GP yang memerlukan pembobotan pada tiap fungsi tujuan, pada FGP tidak perlu pembobotan. Setiap fungsi tujuannya dinyatakan dalam derajat keanggotaan fuzzy sesuai preferensi perusahaan atau pengambil keputusan. Dilihat dari keunggulan ini maka analisis dalam penelitian ini akan menggunakan FGP.

Dari sisi sistem pendukung keputusan (decision support system-DSS) yang merupakan prosedur berbasis model untuk pemrosesan data dan penilaian untuk membantu para manajer mengambil keputusan, mempunyai karakteristik dan kapabilitas yang salah satunya adalah pemodelan dan analisis. Dari sisi klasifikasi DSS, dapat berorientasi data dan model, salah satunya adalah model optimisasi. FGP sebagai model optimisasi, akan membentuk DSS bagi manajemen dari sisi keinginan pengambil keputusan menentukan besarnya nilai setiap fungsi tujuan yang akan dicapai secara optimal (Turban et al. 2005).

Penelitian ini bertujuan untuk membuat formulasi model FGP yang dapat diselesaikan dalam model LP pada perencanaan produksi suatu perusahaan yang dapat memenuhi beberapa tujuan yang ingin dicapai yaitu pendapatan, biaya tenaga kerja, dan biaya bahan baku.

\section{Fuzzy Goal Programming}

Metode yang menggunakan himpunan fuzzy pada GP disebut Fuzzy Goal Programming (FGP), dimana metode ini tidak perlu melakukan kalibrasi pembobotan atau melakukan seleksi terhadap derajat pentingnya fungsi objektif. Metode ini hanya menggunakan preferensi khusus pada tujuan yang dapat dimodelkan dengan menggunakan fungsi-fungsi keanggotaan fuzzy (Kusumadewi \& Purnomo 2004). FGP ini, diformulasi menjadi bentuk LP untuk mencari solusi optimalnya.

Menurut Li et al. (2004), FGP dapat diformulasikan sebagai berikut:

Jika didefinisikan $\boldsymbol{x}=\left[\begin{array}{lll}x_{1}, & x_{2}, \ldots, x_{n}\end{array}\right]^{T} \in R^{n}$ sebagai vektor variabel keputusan dan $f(\boldsymbol{x})=\left(f_{1}(\boldsymbol{x}), \ldots, f_{m}(\boldsymbol{x})\right)$ adalah fungsi-fungsi tujuan dengan sistem bentuk kendala $G(\boldsymbol{x})$. Pengambil keputusan menginginkan batasan $f_{i}^{*},(i=1,2, \ldots m)$ untuk setiap fungsi tujuan yang memenuhi kendala linear $G(\boldsymbol{x})$. Dengan menggunakan konsep himpunan fuzzy, fungsi keanggotaan dapat didefinisikan berdasarkan langkah-langkah berikut:

1. Nyatakan

$$
\begin{array}{r}
\operatorname{Max} f_{i}(\boldsymbol{x}), i=1,2, \ldots, m \\
\text { dengan kendala } \quad \boldsymbol{x} \in G(\boldsymbol{x}) \in R^{n}
\end{array}
$$

misalkan diperoleh $\boldsymbol{x}_{j}{ }^{*}(j=1,2, \ldots, n)$ adalah solusi optimal pada fungsi tujuan $f_{i}(\boldsymbol{x})$, ambil $f_{i}\left(\boldsymbol{x}_{j}^{*}\right)=f_{\text {imax. }}$

2. $\quad$ Cari $\min f_{i}\left(\boldsymbol{x}_{j}^{*}\right)=f_{i \min }$ untuk setiap $i$.

3. Definisikan fungsi keanggotaan $\mu_{f i}(\boldsymbol{x}),(i=1,2, \ldots m)$ dalam bentuk :

$$
\mu_{f i}(\boldsymbol{x})=\left\{\begin{array}{cc}
\frac{f_{\text {imax }}-f_{i}(\boldsymbol{x})}{f_{\text {imax }}-f_{i}{ }^{*}} & f_{i}{ }^{*}<f_{i}(\boldsymbol{x}) \leq f_{\text {imax }} \\
1 & f_{i}(\boldsymbol{x})=f_{i}{ }^{*} \\
\frac{f_{i}(\boldsymbol{x})-f_{\text {imax }}}{f_{i}{ }^{*}-f_{\text {imin }}} & f_{\text {imin }} \leq f_{i}(\boldsymbol{x})<f_{i}{ }^{*}
\end{array}\right.
$$

Kemudian definisikan himpunan $\lambda$-level $F_{i}^{\lambda}(\boldsymbol{x})$ atau $F(\lambda, \boldsymbol{x})$, sehingga dibentuk mode1 FGP yaitu: Tentukan $\boldsymbol{x}^{*}$ yang memenuhi,

$\operatorname{Max} \lambda$

$$
\text { dengan kendala } \quad \boldsymbol{x} \in F(\lambda, \boldsymbol{x}) \cap G(\boldsymbol{x}) \text {. }
$$

dimana $F(\lambda, \boldsymbol{x})=F^{\lambda}(\boldsymbol{x})=F_{1}^{\lambda}(\boldsymbol{x}) \cap F_{2}^{\lambda}(\boldsymbol{x}) \cap \cdots \cap F_{i}^{\lambda}(\boldsymbol{x}) \cap \cdots \cap F_{m}^{\lambda}$

dengan $F_{i}^{\lambda}(\boldsymbol{x})=\left\{\boldsymbol{x} \mid \mu_{f i}(\boldsymbol{x}) \geq \lambda ; 0 \leq \lambda \leq 1, \boldsymbol{x} \in F_{i}(\boldsymbol{x})\right\}$

Karena fungsi tujuan dalam model yang akan dibahas adalah masalah maksimisasi dan minimisasi, menurut Singh et al. (2011), FGP dapat dinyatakan : 
Tentukan $\boldsymbol{x}$

Sedemikian sehingga

$F_{i}(\boldsymbol{x}) \leq f_{i}$ atau $F_{i}(\boldsymbol{x}) \geq f_{i}(i=1,2, \ldots, m)$

dengan kendala

$$
\boldsymbol{A x} \leq \boldsymbol{b}, \boldsymbol{x} \geq 0
$$

dimana $F_{i}(\boldsymbol{x})$ adalah fungsi tujuan ke- $i, f_{i}$ adalah level aspirasi dari fungsi tujuan $F_{i}(\boldsymbol{x}), \boldsymbol{A}$ adalah matriks koefisien penggunaan setiap sumberdaya untuk menghasilkan satu satuan nilai variabel keputusan $x_{j}$, dan $\boldsymbol{b}$ adalah vektor kolom sisi kanan kendala yang menyatakan ketersediaan tiap sumberdaya.

Fungsi keanggotaan $\mu_{f i}(\boldsymbol{x})$ untuk setiap tujuan $f u z z y$ dapat dinyatakan dalam bentuk:

- Jika $F_{i}(\boldsymbol{x}) \leq f_{i}$, maka

$$
\mu_{f i}(\boldsymbol{x})=\left\{\begin{array}{cc}
1 & F_{i}(\boldsymbol{x}) \leq f_{i} \\
\frac{U_{i}-F_{i}(\boldsymbol{x})}{U_{i}-f_{i}} & f_{i} \leq F_{i}(\boldsymbol{x}) \leq U_{i} \\
0 & F_{i}(\boldsymbol{x}) \geq U_{i}
\end{array}\right.
$$

- $\quad$ jika $F_{i}(\boldsymbol{x}) \geq f_{i}$, maka

$$
\mu_{f i}(\boldsymbol{x})=\left\{\begin{array}{cc}
1 & F_{i}(\boldsymbol{x}) \geq f_{i} \\
\frac{F_{i}(\boldsymbol{x})-L_{i}}{f_{i}-L_{i}} & L_{i} \leq F_{i}(\boldsymbol{x}) \leq f_{i} \\
0 & F_{i}(\boldsymbol{x}) \leq L_{i}
\end{array}\right.
$$

dimana $U_{i}$ dan $L_{i}$ adalah batas atas dan bawah preferensi pengambil keputusan yang diinginkan, $f_{i}$ adalah batasan optimal ( $\left.\mathrm{max} / \mathrm{min}\right)$ dari model.

Model FGP (2) dan (3) dapat dinyatakan dalam bentuk :

Tentukan $\boldsymbol{x}^{*}$ yang memenuhi,

$\operatorname{Max} \lambda$

dengan kendala

$$
\begin{aligned}
& \mu_{f i}(\boldsymbol{x}) \geq \lambda \\
& \boldsymbol{A x} \leq \boldsymbol{b}, \quad \boldsymbol{x} \geq 0
\end{aligned}
$$

Selanjutnya fungsi keanggotaan fuzzy tiap fungsi tujuan adalah:

$$
\begin{gathered}
\mu_{f i}(\boldsymbol{x})=\left\{\begin{array}{cc}
1 & F_{i}(\boldsymbol{x}) \leq f_{\text {imin }} \\
\frac{U_{i}-F_{i}(\boldsymbol{x})}{U_{i}-f_{\text {imin }}} & f_{\text {imin }} \leq F_{i}(\boldsymbol{x}) \leq U_{i} \\
0 & F_{i}(\boldsymbol{x}) \geq U_{i}
\end{array}\right. \\
\mu_{f i}(\boldsymbol{x})=\left\{\begin{array}{cc}
1 & F_{i}(\boldsymbol{x}) \geq f_{\text {imax }} \\
\frac{F_{i}(\boldsymbol{x})-L_{i}}{f_{\text {imax }}-L_{i}} & L_{i} \leq F_{i}(\boldsymbol{x}) \leq f_{\text {imax }} \\
0 & F_{i}(\boldsymbol{x}) \leq L_{i}
\end{array}\right.
\end{gathered}
$$

Bentuk fungsi keanggotaan (7) dan (8) dapat digambarkan sebagai berikut :
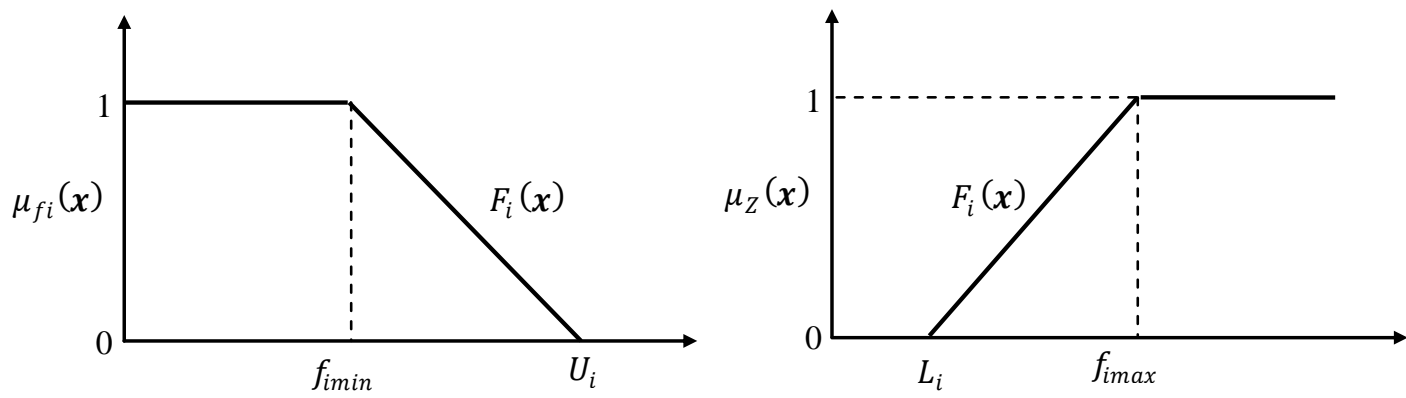

Gambar 1. Bentuk umum fungsi keanggotaan fuzzy fungsi tujuan model FGP 
Semakin besar nilai $\lambda$ yang diperoleh, akan mengakibatkan nilai keanggotaan fuzzy untuk setiap fungsi tujuan akan makin besar yang artinya solusi yang diperoleh mendekati nilai optimal (max/min).

\section{Langkah-langkah Formulasi Model FGP}

- Menetapkan variabel-variabel keputusan : Variabel-variabel keputusan adalah jenis-jenis produk yang diproduksi perusahaan.

- Menetapkan fungsi-fungsi tujuan model : Fungsi tujuan yang akan dianalisa adalah maksimisasi pendapatan, minimisasi biaya bahan baku, dan minimisasi biaya tenaga kerja.

- Menetapkan bentuk-bentuk kendala:

Bentuk-bentuk kendala berhubungan dengan bahan baku yang diperlukan untuk setiap satuan produk yang akan diproduksi dan batasan ketersediaan bahan baku.

- Membentuk model-model LP berdasarkan fungsi tujuan dan kendala yang telah dibentuk.

- Mencari solusi optimal masing-masing model:. Solusi optimal ini didokumentasi sebagai dasar membentuk fungsi keanggotaan fuzzy masingmasing fungsi tujuan.

- Membentuk fungsi keanggotaan dari solusi optimalnya menurut fungsi keanggotan fuzzy: Fungsi keanggotaan fuzzy ini berdasarkan preferensi pengambil keputusan.

- Membentuk model FGP:

Setelah ditentukan solusi dari tujuan mana yang dinyatakan dalam fungsi keanggotaan fuzzy, maka dibuat model FGP. Model ini akan menjadi model dengan satu fungsi tujuan yang dapat dianalisa seperti model LP.

\section{Hasil dan Pembahasan}

Masalah dalam tulisan ini dibatasi pada: tujuan yang di analis is adalah pendapatan, biaya bahan baku, dan biaya tenaga kerja; kendala model adalah bahan baku pembuatan produk dan kemasan/packaging.

\section{Variabel Keputus an}

Variabel keputusan adalah jumlah produksi dari tiap jenis produk yang akan diproduksi yaitu $x_{1}, x_{2}, \ldots, x_{n}$ atau produk ke- $j\left(x_{j}, j=1,2, \ldots, n\right)$

\section{Fungsi Tujuan}

Fungsi tujuan da lam model ini adalah :

- Fungsi pendapatan yang akan dimaksimalkan

$$
\mathrm{Z}(x)=c_{1} x_{1}+c_{2} x_{2}+\cdots+c_{j} x_{j}+\cdots+c_{n} x_{n}=\sum_{j=1}^{n} c_{j} x_{j}
$$

dengan $c_{j}$ adalah harga satu satuan produk ke- $j$, untuk $j=1,2, \ldots, n$.

- Fungsi biaya bahan baku yang akan diminimalkan

$$
B(x)=q_{1} x_{1}+q_{2} x_{2}+\cdots+q_{j} x_{j}+\cdots+q_{n} x_{n}=\sum_{j=1}^{n} q_{j} x_{j}
$$

dengan $q_{j}$ adalah biaya bahan baku yang diperlukan untuk memproduksi satu satuan produk ke- $j$, untuk $j=1,2, \ldots, n$.

- Fungsi biaya tenaga kerja yang akan diminimalkan

$$
T(x)=r_{1} x_{1}+r_{2} x_{2}+\cdots+r_{j} x_{j}+\cdots+r_{n} x_{n}=\sum_{j=1}^{n} r_{j} x_{j}
$$

dengan $r_{j}$ adalah biaya tenaga kerja yang diperlukan untuk memproduksi satu satuan produk ke-j, untuk $j=1,2, \ldots, n$.

\section{Bentuk Kendala}

Bentuk kendala berhubungan dengan ketersediaan sumber daya atau bahan baku.

- Bahan baku pembuatan tiap produk

Misalkan total bahan baku ke- $i$ yang tersedia adalah $b_{i},(i=1,2, \ldots, m)$ dan jumlah bahan baku ke- $i$ yang diperlukan untuk menghasilkan satu satuan produk ke-j adalah $a_{i j}$, maka 
- Kemasan/packaging

$$
\begin{gathered}
a_{11} x_{1}+a_{11} x_{2}+\cdots+a_{11} x_{n} \leq b_{1} \\
a_{21} x_{1}+a_{22} x_{2}+\cdots+a_{2 n} x_{n} \leq b_{2} \\
\vdots \\
\vdots \\
a_{m 1} x_{1}+a_{m 2} x_{2}+\cdots+a_{m n} x_{n} \leq b_{m}
\end{gathered}
$$

Misalkan total kemasan produk ke-j yang tersedia adalah $d_{j},(j=1,2, \ldots, n)$ dan jumlah kemasan produk ke- $j$ yang diperlukan untuk menghasilkan satu satuan produk ke- $j$ adalah $v_{j}$, maka $v_{j} x_{j} \leq d_{j}$.

Ditambah dengan kendala nonnegatif yaitu $x_{j} \geq 0$.

\section{Model FGP}

Untuk membentuk model FGP, perlu dicari terlebih dahulu solusi LP untuk masing-masing fungsi tujuan.

Misalkan untuk :

(1) $\operatorname{Max} Z(x)$ diperoleh $Z\left(x^{*}\right)=Z^{*}$

(2) $\operatorname{Min} B(x)$ diperoleh $B\left(x^{*}\right)=B^{*}$

(3) Min $T(x)$ diperoleh $T\left(x^{*}\right)=T^{*}$

Nilai-nilai ini akan menjadi batas maksimum dan minimum pada fungsi keanggotaan fuzzy dari masing-masing fungsi tujuan. Selanjutnya manajerial pengambil keputusan perusahaan dapat menentukan tingkat pendapatan terendah dengan tingkat biaya bahan baku dan tenaga kerja tertinggi yang diinginkan.

Misalkan yang diinginkan adalah:

- Serendah-rendahnya pendapatan yang harus diperoleh adalah $\bar{Z}$

- Setinggi-tingginya biaya bahan baku adalah $\bar{B}$

- Setinggi-tingginya biaya tenaga kerja adalah $\bar{T}$

Maka fungsi keanggotaan fuzzy dari setiap fungsi tujuan adalah :

$$
\begin{aligned}
& \mu_{Z}(x)=\left\{\begin{array}{cc}
1 & Z(x) \geq Z^{*} \\
\frac{Z(x)-\bar{Z}}{Z^{*}-\bar{Z}} & \bar{Z} \leq Z(x) \leq Z^{*} \\
0 & Z(x) \leq \bar{Z}
\end{array}\right. \\
& \mu_{B}(x)=\left\{\begin{array}{cc}
1 & B(x) \leq B^{*} \\
\bar{B}-B(x) & B^{*} \leq B(x) \leq \bar{B} \\
0 & B(x) \geq \bar{B}
\end{array} \quad \mu_{T}(x)=\left\{\begin{array}{cc}
1 & T(x) \leq T^{*} \\
\overline{\bar{T}-T(x)} & T^{*} \leq T(x) \leq \bar{T} \\
\overline{\bar{T}-T^{*}} & T(x) \geq \bar{T}
\end{array}\right.\right.
\end{aligned}
$$
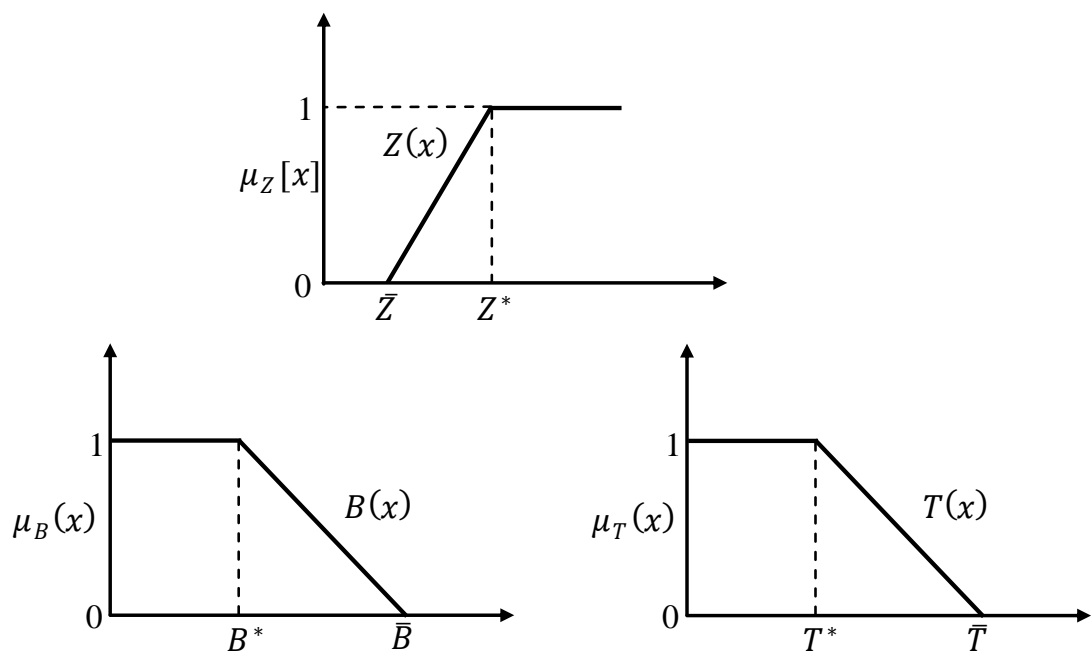

Gambar 2. Fungsi keanggotaan fuzzy dari tiap fungsi tujuan model 
Berdasarkan model (6), dan fungsi keanggotaan fuzzy (7) dan (8), maka :

- Untuk $\mu_{Z}(x)=\frac{Z(x)-\bar{Z}}{Z^{*}-\bar{Z}}$ pada selang $\bar{Z} \leq Z(x) \leq Z^{*}$, dimana $\bar{Z}$ dan $Z^{*}$ bernilai real, berlaku :

$$
c_{1} x_{1}+c_{2} x_{2}+\cdots+c_{n} x_{n}-\left(Z^{*}-\bar{Z}\right) \lambda \geq \bar{Z}
$$

- Untuk $\mu_{B}(x)=B^{*} \leq B(x) \leq \bar{B}$ pada selang $B^{*} \leq B(x) \leq \bar{B}$, dimana $B^{*}$ dan $B$ bernila $\mathrm{i}$ real, berlaku :

$$
q_{1} x_{1}+q_{2} x_{2}+\cdots+q_{j} x_{j}+\cdots+q_{n} x_{n}+\left(\bar{B}-B^{*}\right) \lambda \leq \bar{B}
$$

- Untuk $\mu_{T}(x)=T^{*} \leq T(x) \leq \bar{T}$ pada selang $T^{*} \leq T(x) \leq \bar{T}$, dimana $T^{*}$ dan $T$ bernilai real, berlaku :

$$
r_{1} x_{1}+r_{2} x_{2}+\cdots+r_{j} x_{j}+\cdots+r_{n} x_{n}+\left(\bar{T}-T^{*}\right) \lambda \leq \bar{T}
$$

Model FGP yang diperoleh adalah :

$\operatorname{Max} \lambda$

dengan kendala

$$
\begin{aligned}
& c_{1} x_{1}+c_{2} x_{2}+\cdots+c_{n} x_{n}-\left(Z^{*}-\bar{Z}\right) \lambda \geq \bar{Z} \\
& q_{1} x_{1}+q_{2} x_{2}+\cdots+q_{j} x_{j}+\cdots+q_{n} x_{n}+\left(\bar{B}-B^{*}\right) \lambda \leq \bar{B} \\
& r_{1} x_{1}+r_{2} x_{2}+\cdots+r_{j} x_{j}+\cdots+r_{n} x_{n}+\left(\bar{T}-T^{*}\right) \lambda \leq \bar{T} \\
& a_{11} x_{1}+a_{12} x_{2}+\cdots+a_{1 n} x_{n} \leq b_{1} \\
& a_{21} x_{1}+a_{22} x_{2}+\cdots+a_{2 n} x_{n} \leq b_{2} \\
& \quad \vdots \\
& \quad \vdots \\
& a_{m 1} x_{1}+a_{m 2} x_{2}+\cdots+a_{m n} x_{n} \leq b_{m} \\
& v_{j} x_{j} \leq d_{j}, x_{j} \geq 0 .
\end{aligned}
$$

dimana :

$x_{1}, x_{2}, \ldots, x_{n}:$ jumlah produksi dari tiap jenis produk ke-j

$c_{1}, c_{2}, \ldots, c_{n}$ : harga satuan tiap jenis produk ke-j

$q_{1}, q_{2}, \ldots, q_{n}$ : biaya bahan baku yang diperlukan untuk memproduksi satu satuan produk ke-j

$r_{1}, r_{2}, \ldots, r_{n}$ : biaya tenaga kerja yang diperlukan untuk memproduksi satu satuan produk ke-j

$a_{11}, a_{12}, \ldots, a_{m n}$ : jumlah bahan baku ke- $i$ yang diperlukan untuk menghasilkan satu satuan produk ke-j

$b_{1}, b_{2}, \ldots, b_{m}:$ total ketersediaan bahan baku ke- $i$

$v_{j} \quad:$ jumlah kemasan produk ke-j yang diperlukan untuk menghasilkan satu satuan produk ke-j

$d_{j} \quad:$ total ketersediaan kemasan produk ke- $j$

$Z^{*} \quad$ : pendapatan optimal pada solusi model LP

$B^{*} \quad$ : biaya bahan baku optimal pada solusi model LP

$T^{*} \quad$ : biaya tenaga kerja optimal pada solusi model LP

$\bar{Z} \quad$ : pendapatan terendah yang harus diperoleh

$\bar{B} \quad$ : biaya bahan baku tertinggi yang digunakan

$\bar{T} \quad$ : biaya tenaga kerja tertinngi yang digunakan.

Model FGP ini merupakan model yang dapat diselesaikan dalam bentuk LP dengan variabel keputusan $\lambda$ yang menentukan nilai keanggotaan fuzzy-nya dan $x_{1}, x_{2}, \ldots, x_{n}$ sebagai jumlah tiap jenis produk yang akan diproduksi. 


\section{Kesimpulan}

- Model beberapa tujuan dalam linear programming (LP) dapat diformulasi dalam bentuk Fuzzy Goal Programming (FGP) berdasarkan preferensi pengambil keputusan pada setiap tujuan yang ingin dicapai.

- Formulasi FGP dapat diselesaikan dalam model LP.

- Formulasi FGP ini, dapat diterapkan pada perencanaan produksi perusahaan.

\section{Daftar Pustaka}

Chankong V., Y.Haimes. 1993. Multiobjective Decision Making: Theory and Methodology. New York .

Chodary B., J.Slomp. 2002. Production Planning Under Dynamic Product Environment:

A Multi-objective Goal Programming Approach. http://www.ub.rug.n1/eldoc/som/a/02A12/02A12.pdf [15 Des 2009].

Cukas M. 2008. Design Optimization of Electric Motor by Multiobjective Fuzzy. Mathematics and Computational Application 13(3): 153 - 163.

Li S., Y.Yang, C.Teng. 2004. Fuzzy Goal Programming With Multiple Priorities via Generalized Verying-Domain Optimization Method. IEEE Transactions on Fuzzy System 12(5): $597-605$.

Singh P., S.T.Kumar, R.K.Singh. 2011. Fuzzy Goal Programming Approach to Multiobjective Linear Plus Linaer Fractional Programming Problem. WSEAS Proceedings of American Conference on Applied Mathematics Puerto Morelos, Mexico.

Turban E., J.E.Aronson, T.P.Liang. 2005. Decision Support System and Intelligent System. Seventh Edition. Pearson Prentice Hall. USA. 